\title{
Damage tolerance assessment by bend and shear tests of two multilayer composites: glass fibre reinforced metal laminate and aluminium roll-bonded laminate
}

C.M. Cepeda-Jiménez ${ }^{(1)} *$, R.C. Alderliesten ${ }^{(2)}$, O.A. Ruano ${ }^{(1)}$, F. Carreño ${ }^{(1)}$

(1) Department of Physical Metallurgy, CENIM, CSIC, Av. Gregorio del Amo 8, 28040 Madrid, Spain

${ }^{(2)}$ Delft University of Technology, Faculty of Aerospace Engineering, Structures and Materials Laboratory, P.O. Box 5058, 2600 GB Delft, The Netherlands

\begin{abstract}
The damage tolerance of an aluminium roll-bonded laminate (ALH19) and a glass fibre reinforced laminate (GLARE) (both based in Al 2024-T3) has been studied. The composite laminates have been tested under 3-point bend and shear tests on the interfaces to analyze their fracture behaviour. During the bend tests different fracture mechanisms were activated for both laminates, which depend on the constituent materials and their interfaces. The high intrinsic toughness of the pure Al 1050 layers present in the aluminium roll-bonded laminate (ALH19), together with extrinsic toughening mechanisms such as crack bridging and interface delamination were responsible for the enhanced toughness of this composite laminate. On the other hand, crack deflection by debonding between the glass fibres and the plastic resin in GLARE, was the main extrinsic toughening mechanism present in this composite laminate.
\end{abstract}

Keywords: A. Aluminium alloys; A. Laminates; B. Delamination; B. Interfacial strength; C. Fracture mechanisms.

*Corresponding author. Tel.: +34 91 5538900; fax: +34 915347425.

E-mail address: cm.cepeda@cenim.csic.es (C.M. Cepeda-Jiménez)

\section{Introduction}

In the last decades, multilayered structures can be readily fabricated with proper control over interfacial and constituent properties. This control over the fabrication process enables the design of materials with optimally tailored fracture toughness and mechanical behaviour [1-4]. Fibre/metal laminates (FMLs) have emerged as viable materials for aeronautical applications, thanks to their excellent fatigue and damage resistance, impact properties, possibility of inspection after impact threats, ease of machinability and formability [5,6]. FMLs were developed at Delft University of Technology as a family of hybrid materials that consist of bonded thin aluminium sheets 
and fibres embedded in epoxy resin [7]. The most outstanding FML is GLARE, which consists of thin aluminium 2024-T3 layers, bonded together with glass fibres embedded in epoxy resin. On the other hand, a previous work [8] showed that it is possible to obtain aluminium multilayer materials with high impact toughness by hot roll-bonding processing.

The utilization of multilayer laminates in large transport aircraft structures is conditioned to their damage tolerance properties [9]. As a consequence, the damage tolerance concept is becoming highly important in material design, in order to warrant structural integrity under the occurrence of any damage.

Traditionally Charpy impact test has been used to evaluate the relative toughness of materials, being an economical quality control method to asses the notch sensitivity of engineering materials. In this work, bend tests have been selected because they deliver much more useful information about the mechanical properties and damage tolerance of the composite laminates than the Charpy impact test. The bend tests of Vnotched Charpy samples allow determination of yield and maximum stresses, a graphical visualization of layer fracture and the different fracture mechanisms as testing proceeds, and finally, comparison of toughness values by comparison of the areas inside the load-displacement curves. Additionally, the shear test allows quantitative assessment of the bond between layers, permitting prediction of possible delaminations, and thus, the damage tolerance of the layered material.

Therefore, the objective of the present work is to compare mechanical properties obtained by bend and shear tests of an aluminium multilayer composite with GLARE, analyzing the fracture mechanisms responsible for the impact damage resistance improvement. Furthermore, it is presented an alternative aluminium multilayer composite with high strength and outstanding toughness processed by high temperature roll bonding, which is a relative simple technique that can be carried out in a conventional rolling plant using parameters that are easy to control (e.g. percentage reduction, rolling speed, roll diameter, processing temperature, etc.).

\section{Experimental procedure}

\subsection{Materials and processing}

The aluminium alloys used were rolled Al 2024-T3 alloy (termed "L”) of 2 mm in thickness and foils of commercial pure $\mathrm{Al} 1050-\mathrm{H} 24$ (termed "H") of $0.5 \mathrm{~mm}$ in thickness. The main alloying elements of the $\mathrm{Al} 2024$ alloy are $\mathrm{Cu}$ (4.43 wt.\%), Mg (1.33 wt.\%) and Mn (0.62 wt.\%). Ten Al 2024 alloy layers and nine Al 1050 layers were stacked alternately, making up a bundle of $24.5 \mathrm{~mm}$ in thickness, $60 \mathrm{~mm}$ in width and $150 \mathrm{~mm}$ in length and referenced in this work as ALH19. The stacked aluminium composite material was welded by Tungsten Inert Gas (TIG) at their edges and then hot- 
rolled at $465{ }^{\circ} \mathrm{C}$ in four series of four passes of about $4-8 \%$ reduction per pass, corresponding to an equivalent true strain of $\in=0.96$ (according to Von Misses criterion). The sample was reheated between series. The diameter of the rolls was 130 $\mathrm{mm}$ and the rolling speed was $346 \mathrm{~mm} / \mathrm{s}$. The composite laminate was rolled parallel to the rolling direction of the as-received sheets. This rolling was carried out at high temperature and the laminate was cooled slowly to room temperature. A T6 heat treatment was given subsequently to optimize the mechanical properties of the $\mathrm{Al} 2024$ alloy included in the laminate material. This heat treatment involves solution treating the alloy at $495{ }^{\circ} \mathrm{C}$ for $30 \mathrm{~min}$, followed by rapid quenching in water and finally age hardening at $160{ }^{\circ} \mathrm{C}$ for $16 \mathrm{~h}$. The resulting hot-rolled composite laminate was in the form of a plate, of thickness about $11 \mathrm{~mm}$, length about $350 \mathrm{~mm}$ and width about 60 mm. The thickness of the Al 2024 layers in the ALH19 was $\sim 910 \mu \mathrm{m}$ and that of the pure Al 1050 layers was $\sim 250 \mu \mathrm{m}$.

The GLARE laminate used in the present study was a composite laminate with four $\mathrm{Al}$ 2024-T3 layers of $0.4 \mathrm{~mm}$ thickness with in-between uni-directional fibre layers and coded as Glare 2A-4/3-0.4, which refers to, respectively, the GLARE grade, the layup and the aluminium layer thickness. More details on other GLARE configurations are given elsewhere [10]. The fibre reinforced composite, under form of rectangular panel $400 \mathrm{~mm}$ in length, $192 \mathrm{~mm}$ in width and $2.3 \mathrm{~mm}$ in thickness, was fabricated at Delft University of Technology. Rectangular specimens $\left(10 \times 2 \times 2.3 \mathrm{~mm}^{3}\right)$ were cut and polished according to metallographic techniques and observed under an optical microscope to precisely evaluate the thickness of the constituent layers. The thickness of $\mathrm{Al}$ sheets resulted to be $\sim 390 \mu \mathrm{m}$ and that of the glass fibre reinforced resin layers $\sim 290 \mu \mathrm{m}$.

\subsection{Mechanical tests}

The mechanical behaviour of the multilayer composite laminates was measured by three point bend tests and shear tests. The bending was performed using a Servosis universal test machine under displacement control at a rate of $0.04 \mathrm{~mm} / \mathrm{s}$. Figure 1 shows a macrograph of a bend tested sample on the bending tool used in this study. The as-received $\mathrm{Al} 2024$ and pure $\mathrm{Al} 1050$ monolithic materials and the composite laminates were tested in the crack arrester orientation. The rolled microstructure in the as-received aluminium materials, with elongated grains in the rolling direction, permits to distinguish two different orientations. Thus, for the as-received materials, in the socalled crack arrester orientation the notch tip is parallel to the plane and rolling directions. For the laminate materials, in the crack arrester orientation the crack is forced to pass through each layer sequentially, and it is the natural configuration for an aluminium panel in an airplane. This configuration is the most interesting, both technically and scientifically, to study the different fracture mechanisms operating 
during the bend test. Two mm V-notched Charpy type specimens $\left(10 \times 10 \times 55 \mathrm{~mm}^{3}\right)$ in the crack-arrester orientation were machined from the as-received materials and the ALH19 composite laminate to carry out the bend test, being the loading span $40 \mathrm{~mm}$. For the GLARE laminate, rectangular specimens $\left(2.3 \times 10 \times 55 \mathrm{~mm}^{3}\right)$ were cut and Vnotched (0.47 mm depth) also in the crack-arrester orientation and bend tested with a loading span of $20 \mathrm{~mm}$ in order to obtain similar deformation. On the other hand, the ratio notch depth/laminate thickness was approximately the same for both multilayer materials in order to conserve similar aspect ratio. The glass fibres orientation in the prepreg layer was perpendicular to the notch tip, being the most favourable orientation to obtain the maximum stiffness and strength during bending loads. The fibres in the composite are strong and stiff and support most of the applied loads. Three samples of each material were bend tested.

A representation of the true raw data, load vs. displacement, was used in order to characterize the mechanical response to layer fracture and crack propagation across the composite laminates, which is an assessment of damage tolerance. Additionally, and in order to take into account the different laminate thicknesses, nominal stress vs. nominal strain was also represented for comparison. The nominal stress, $\sigma$, and the nominal strain, $\varepsilon$, were converted from the recorded raw data according to the following relations [11]:

$$
\sigma=\frac{3 p l}{2 a e^{2}} \quad \varepsilon=\frac{6 e d}{l^{2}}
$$

where $a$ is the initial width of the sample, $e$ is the initial thickness of the sample minus the $\mathrm{V}$-notch depth, $l$ is the span length between the supports, $p$ is the force applied on the sample and $d$ is the midspan displacement of the sample. Fracture surfaces of selected specimens were examined by both macroscopic observations and optical microscopy to evaluate deformation micromechanisms during crack propagation. Metallographic preparation involved methods of standard surface preparation.

The interface mechanical properties were measured by shear test in a Servosis universal test machine at a cross-head rate of $0.005 \mathrm{~mm} / \mathrm{s}$, using specimens of approximate dimensions 10x10x3 $\mathrm{mm}^{3}$ for the ALH19 composite laminate and 10x2.3x1.5 $\mathrm{mm}^{3}$ for GLARE. The test was performed by clamping the sample between two metal supports (Figure 2). The interface to be tested is located just outside the border of the tool and parallel to the load direction. Then, a square punch at a given gap distance is used to apply the shear load until failure of the interface. The shear stress, $\tau$, and the shear strain, $\gamma$, are given by the expressions [12]

$$
\tau=\frac{p}{a e} \quad \gamma=\tan (\alpha)=\frac{d}{l_{\text {gap }}}
$$


where $a, e, p$ and $d$ have been already defined, $\alpha$ is the shear angle and $l_{g a p}$ is the span length between the supports and the mobile punch, corresponding to $0.35 \mathrm{~mm}$ in this study.

\section{Results and discussion}

Figure 3 shows load-displacement (Fig. 3a and $\mathbf{3 b}$ ) and nominal stress-nominal strain (Fig 3c) curves obtained from three point bend tests. Figure 3a includes F-d

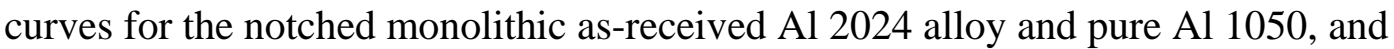
ALH19 roll-bonding laminate, which were $10 \mathrm{~mm}$ in thickness. Separately, a loaddisplacement curve for GLARE is shown in Figure 3b. All materials were tested in bending in the crack arrester orientation. Additionally, and for comparison, Figure 3c include nominal stress vs. nominal strain curves for all considered materials in this work. As it has been mentioned previously, the objective of representing nominal parameters is to compare samples with different thickness and to evaluate their damage tolerance. As shown in Figs. 3a and 3c, the Al 2024 alloy presents a high bending strength (750 MPa) and limited ductility. In contrast, the pure $\mathrm{Al} 1050$ presents low bending strength (237 MPa) but excellent plasticity. The ALH19 composite laminate has a maximum bending stress of $595 \mathrm{MPa}$. GLARE laminate shows a maximum bending stress of $689 \mathrm{MPa}$ (Figure 3c). The ductility for both composite laminates is outstanding due to different intrinsic and extrinsic mechanisms of fracture that will be analysed later. Accordingly, the outstanding increase in ductility and the high mechanical strength observed in both laminate composites can be associated with high damage tolerance. Additionally, the figures clearly reveal differences between the fracture mechanisms of both laminate materials, which are consequence of the properties of the constituent materials and their interfaces. The curve corresponding to the ALH19 composite laminate (Fig 3a) shows first some strain hardening (1) and then drops in load when cracking occurs in the more brittle Al 2024 layers (2 and 5), followed by gradual crack arrest in the pure $\mathrm{Al} 1050$ layers (3) due to its high toughness (intrinsic toughening mechanism). The short plateau in the F-d curve (4) indicates plastic deformation of the remaining material while the main crack is slowly propagating across the pure Al 1050 layer until a new drop through the Al 2024 layer occurs. The slow and stepped crack propagation across the ALH19 composite laminate compared to $\mathrm{Al} 2024$ alloy increases noticeably the area inside the F-d curve and thus the material toughness. On the other hand, the GLARE laminate (Fig. 3b) shows a first load drop which coincides with cracking of the notched Al 2024 layer (6) until the crack is arrested in the resin layer by the debonding of the glass fibres with the epoxy resin. Debonded fibres act like unbroken ligaments bridging the main crack, being necessary additional bend deformation to fracture them (classical "fibre bridging" fracture mechanism). The high damage tolerance of the GLARE material is mainly due to this 
fracture mechanism. Thus, the debonding between the glass fibres and the epoxy matrix produces crack deflection by delamination (extrinsic toughening mechanisms). Then, extensive strain hardening (7) is observed due mainly to the contribution of the high ultimate tensile strength of the glass fibres and also to the plastic deformation of the remaining material. Above a given load, the aluminium starts to deform plastically while the fibres are still in the elastic regime. This causes high shear stresses in the resin-rich layer [13] which favours delamination. As deformation proceeds, delaminations shift the support point of the fibres during the bend test, being necessary further deformation and stress to fracture them, increasing the GLARE strength. Thus, the ultimate strain of the fibres (8) controls the ultimate flexure stress. Finally after the large load drop due to the cracking of the fibres, the plateau region (9) correspond to plastic deformation of the remaining material until the next load drop occurs, indicating that the critical strain needed for crack renucleation in the next aluminium layer is reached.

Figure 4 shows at different magnifications SEM and optical micrographs of the crack propagation sequence in the ALH19 composite laminate during the bend test. The main crack (Fig 4a) initiated at the notch tip (1) in a pure Al 1050 layer, and then propagated through this and the next Al 2024 layer (2) under mode I (opening) conditions, until it is arrested at the pure $\mathrm{Al} 1050$ layer (3) by an intrinsic mechanism, due to its inherent toughness offering high resistance to the crack growth (Figure $\mathbf{4 b}$ ). While the main crack is being retarded at the pure aluminium layer, other two extrinsic fracture mechanisms (Figure 4c) named “crack bridging” (4) and “interface delamination” (5) occur. According to the crack bridging mechanism, different cracks reinitiate (4) in the next $\mathrm{Al} 2024$ layer before the main crack reaches it, because its bend failure strain is reached. Thus, in this extrinsic toughening mechanism, unbroken ligaments in the pure $\mathrm{Al} 1050$ and $\mathrm{Al} 2024$ alloy in the wake of the crack prevent catastrophic crack propagation due to the "bridging" of the crack. Crack growth requires stretching of the bridging ligaments with additional energy absorption. On the other hand, in the "interface delamination" mechanism (5) the next interface is delaminating locally before the main crack reaches it due to the stresses that the interface has to stand when the bending test proceeds. This mechanism results in a reduction and redistribution of the local stress and warrants further delamination and renucleation of a new crack, thus improving ductility. The combination of these fracture mechanisms (intrinsic and extrinsic) is responsible for the enhanced damage tolerance of the ALH19 composite laminate.

Figure 5 shows a macrograph of GLARE laminate after bend testing. The macrograph illustrates the fracture of glass fibres after high tensile strain. Also debonding between fibres and resin matrix is clearly evidenced. The GLARE laminate 
presents several delaminations, together with extensive plastic deformation of $\mathrm{Al} 2024$ layers necessary to induce crack renucleation.

To precisely characterize the mechanical properties of interfaces, which are the main responsible of the fracture mechanisms and the damage tolerance improvement observed, shear tests along them have been performed (Figure 6). The interfaces in the ALH19 composite laminate are assigned numbers to indicate their location in the laminate (for example, i4 means interface four). Two possible fibres orientation (vertical and horizontal) were considered for shearing along the interfaces of the GLARE laminate and only the middle interface of different samples was tested due to the small thickness of the GLARE laminate. For comparison, monolithic pure Al 1050 $(\mathrm{H})$ and $\mathrm{Al} 2024$ (L) alloy are also included. The maximum shear stress of the Al 2024 (L) alloy is $232 \mathrm{MPa}$ (scaled on the right ordinate axis), and the plastic shear deformation is 1.19. In contrast, the maximum shear stress of pure $\mathrm{Al} 1050$ is only 58 MPa, but it is much more ductile ( $\left.\gamma_{\text {plast.max. }}=6.5\right)$. Regarding the composite laminates, the interfaces of the ALH19 laminate are ductile, having elongation to failure values $\left(\gamma_{\text {plast.max }} \sim 6\right)$ similar to the monolithic pure Al 1050. On the other hand, the shear strength is slightly higher than for the pure $\mathrm{Al} 1050$ which may be attributed to grain refinement strengthening due to the rolling process. Failure occurred in the $\mathrm{Al} 1050(\mathrm{H})$ next to the interface. Thus, the bond strength exceeds the fracture strength of the weaker component (Al 1050), an indication of high bond integrity. It is worth noting that in ALH19 laminate only one type of interfaces is present between aluminium layers. In contrast, two interface types are possible in the GLARE material: epoxy-aluminium interface and epoxy-fibre interface. The interfaces of the GLARE laminate show lower shear strength than those of the ALH19 composite laminate, especially for horizontal fibre orientation which is perpendicular to the applied load direction, and very low ductility $\left(\gamma_{\text {plast.max }}<1\right)$ with a cohesive failure in the epoxy matrix which was evidenced by the presence of fibres in both shear fractured surfaces. This is consistent with an adhesion failure in the epoxy-fibre interface between the glass fibres and epoxy resin. The low shear strength of the glass fibre reinforced polymer layer induces delamination growth under bend loads increasing the toughness by an extrinsic crack deflection mechanism. Therefore, the shear strength of the adhesive and the bonding with the glass fibres play an important role in the possible occurrence of extrinsic toughening mechanisms, such as delamination, during loading. Finally, Figure 7 shows an optical micrograph of the as-received glass fibre reinforced plastic layer. The figure shows the glass fibres embedded in resin matrix and some debonding between the fibres and the epoxy adhesive, marked with arrows, which would be in agreement with the low shear strength of the adhesive layer observed in the shear tests. 


\section{Conclusions}

Damage tolerance and fracture mechanisms of two multilayer composite laminates based in different constituent materials have been assessed by three point bend and shear tests. A multilayer laminate composite of Al 2024 and Al 1050 has been processed by hot-roll bonding, resulting in a material of high bend strength and ductility, which can be associated with high impact toughness and damage tolerance that could be competitive with the GLARE material. The fracture mechanisms of the multilayer composite laminates depend on the properties of the constituent materials and their interfaces. The high intrinsic toughness of pure Al 1050 layers and extrinsic mechanisms such as crack bridging and interface delamination were mainly responsible of crack arresting in the bend test of the ALH19 laminate. On the other hand, crack deflection by debonding between the glass fibres and the epoxy matrix was responsible of the high damage tolerance of the GLARE material.

\section{Acknowledgements}

Financial support from CICYT (Project MAT2003-01172) is gratefully acknowledged. C.M. Cepeda-Jiménez thanks the Spanish Ministry of Education and Science for a Juan de la Cierva contract. Authors also thank Delft University of Technology for providing the GLARE.

\section{References}

[1] Wang Y-C, Misra A, Hoagland RG._Fatigue properties of nanoscale $\mathrm{Cu} / \mathrm{Nb}$ multilayers. Scripta Mater 2006;54:1593-1598.

[2] Singh RP, Parameswaran V. An experimental investigation of dynamic crack propagation in a brittle material reinforced with a ductile layer. Opt Laser Eng 2003;40:289-306.

[3] Li YP, Zhang GP, Wang W, Tan J, Zhu SJ. On interface strengthening ability in metallic multilayers. Scripta Mater 2007;57:117-120.

[4] Pozuelo M, Carreño F, Ruano OA. Delamination effect on the impact toughness of an ultrahigh carbon-mild steel laminate composite. Compos Sci Tech 2006;66:26712676.

[5] Iaccarino P, Langella A, Caprino G. A simplified model to predict the tensile and shear stress-strain behaviour of fibreglass/aluminium laminates. Compos Sci Tech 2007;67:1784-1793.

[6] Azeem MA, Shortall C, Ramamurty U. Tensile properties of stainless steel sandwich sheets with fibrous cores. Scripta Mater 2007;57:221-224. 
[7] Alderliesten RC, Schijve J, van der Zwaag S. Application of the energy release rate approach for delamination growth in glare. Eng Fract Mech 2006;73:697-709.

[8] Cepeda-Jiménez CM, Pozuelo M, Ruano OA, Carreño F. Influence of the thermomechanical processing on the fracture mechanisms of high strength aluminium/pure aluminium multilayer laminate materials. Mater Sci Eng A 2008;490:319-327.

[9] Roudolff F, Gädke M. Damage tolerance of composite structures for large transport aircraft. Aerosp Sci Technol 2000;4:23-32.

[10] Alderliesten RC, Campoli G, Benedictus R. Modelling cyclic shear deformation of fibre/epoxy layers in fibre metal laminates. Compos Sci Tech 2007;67:2545-2555.

[11] Gere JM, Timoshenko SP. Mechanics of Materials. PWS, Boston, MA, 1997.

[12] Dieter GE. Mechanical Metallurgy. SI Metric, UK, 1988, pp.12-15.

[13] de Vries TJ, Vlot A. The influence of the Constituent Properties on the Residual Stength of GLARE. Appl Compos Mater 2001;8:263-277. 


\section{Figure Captions}

Figure 1. Macrograph of a bend tested sample.

Figure 2. Scheme of the shear test.

Figure 3. Three point bend test of notched as-received Al 2024-T3 alloy and pure Al 1050-H24, and ALH19 and GLARE composite laminates in crack arrester orientation. a) and b) Load-displacement curves; c) Stress-strain curves.

Figure 4. a) SEM and b) and c) optical micrographs of a bend tested ALH19 composite laminate showing different fracture mechanisms as a function of the constituent materials: b) Crack arresting in pure $\mathrm{Al} 1050$ layers by an intrinsic toughening mechanism; c) Crack bridging and interface delamination.

Figure 5. Macrograph of fractured bend tested GLARE sample.

Figure 6. Shear test of as-received pure Al 1050-H24 and Al 2024-T3 alloy, and on different interfaces of ALH19 and GLARE composite laminates.

Figure 7. Optical micrograph of the fibre glass reinforced plastic layer of as-received GLARE showing the glass fibres embedded in resin matrix. The arrows indicate fibreresin debonding. 


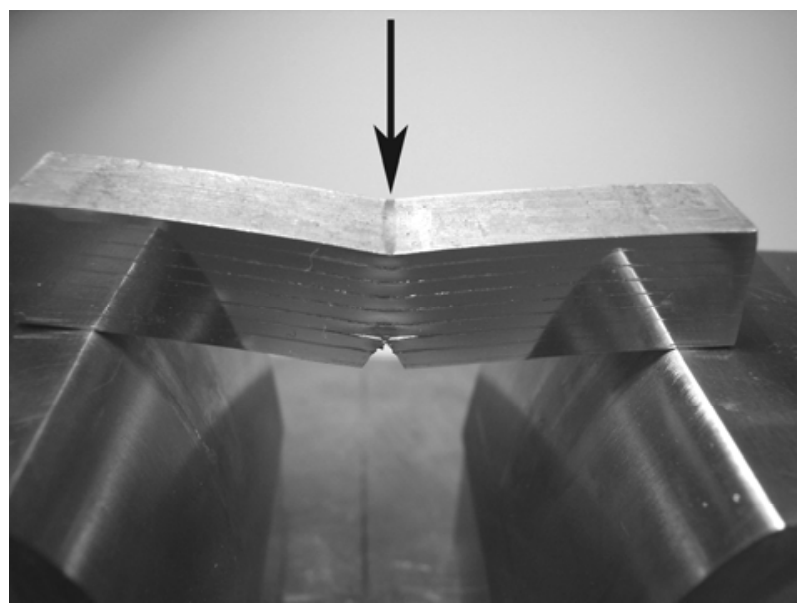

Figure 1

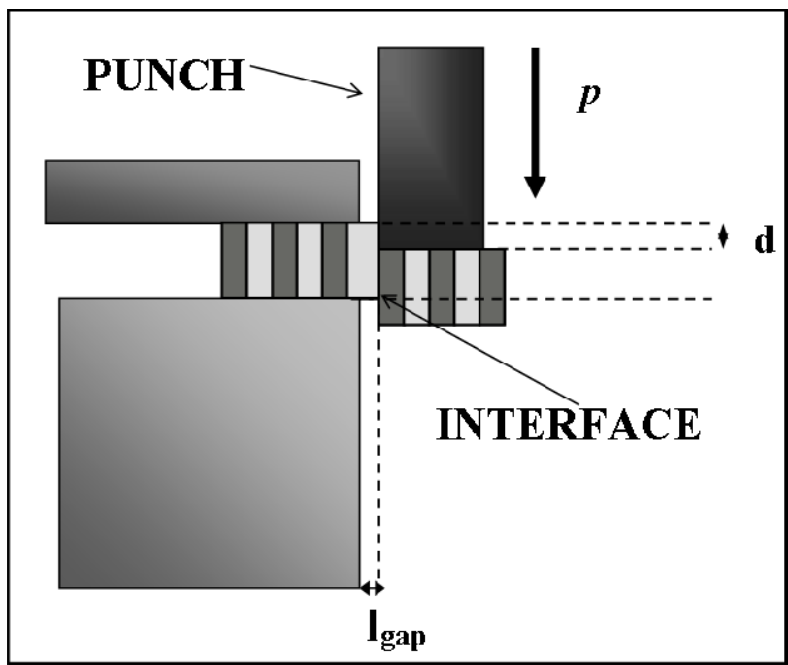

Figure 2 
a)

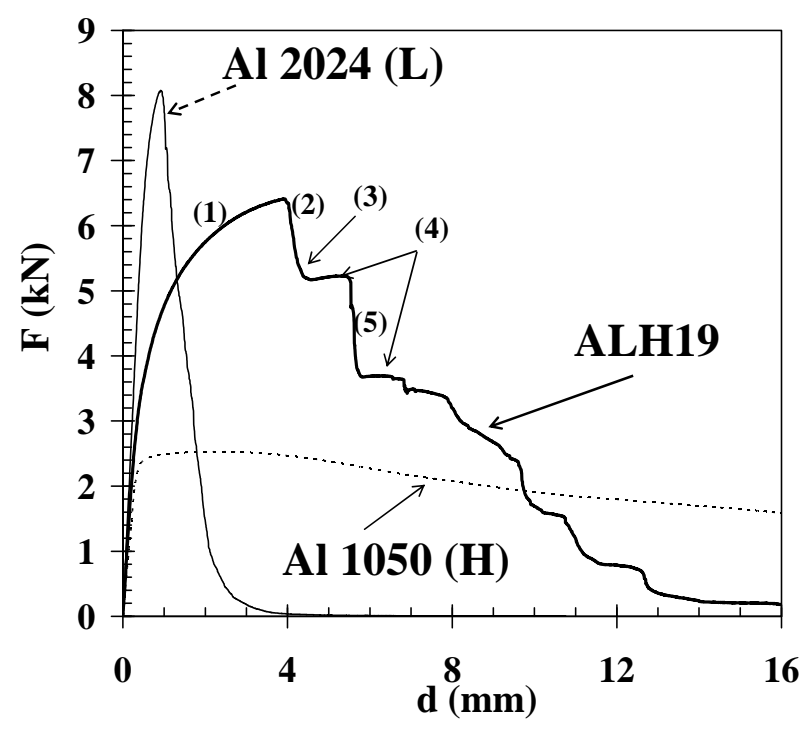

b)

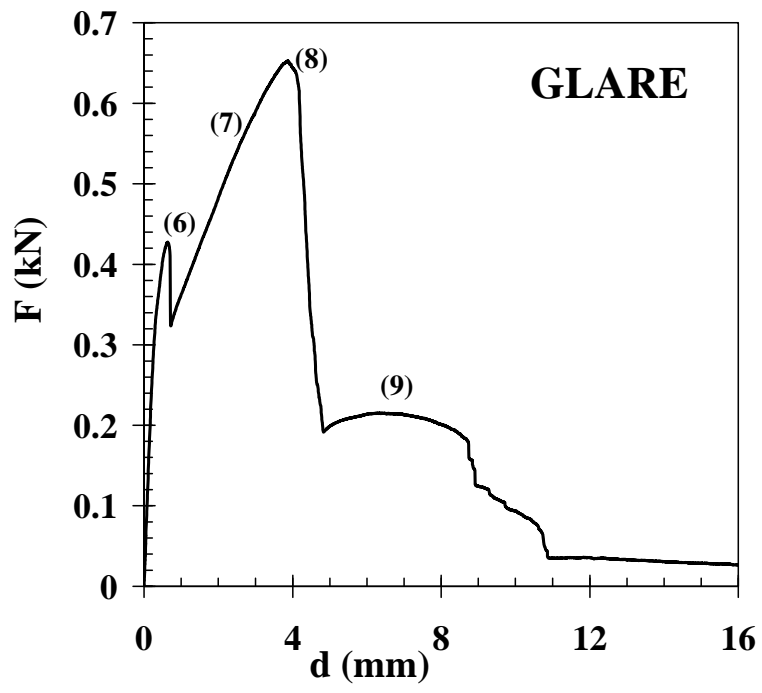

c)

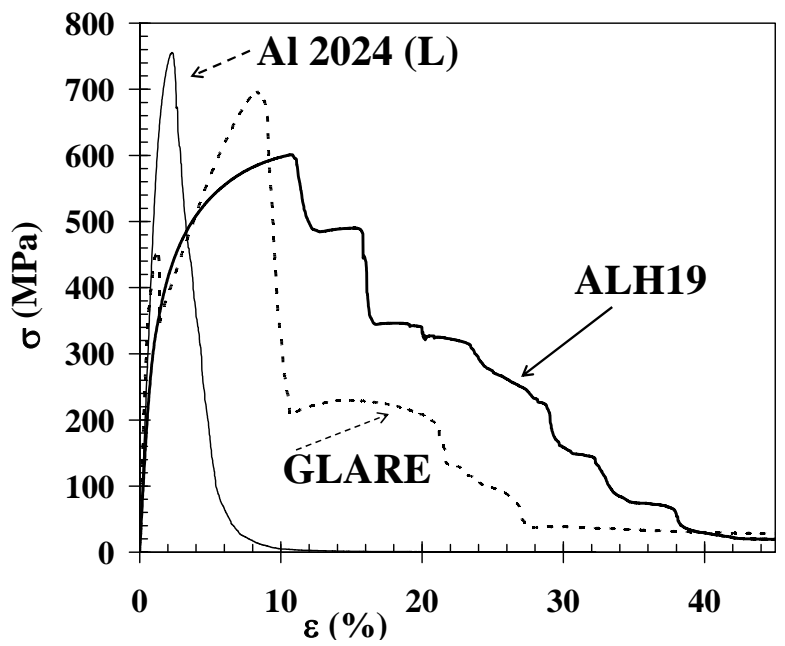

Figure 3 
a)

b)
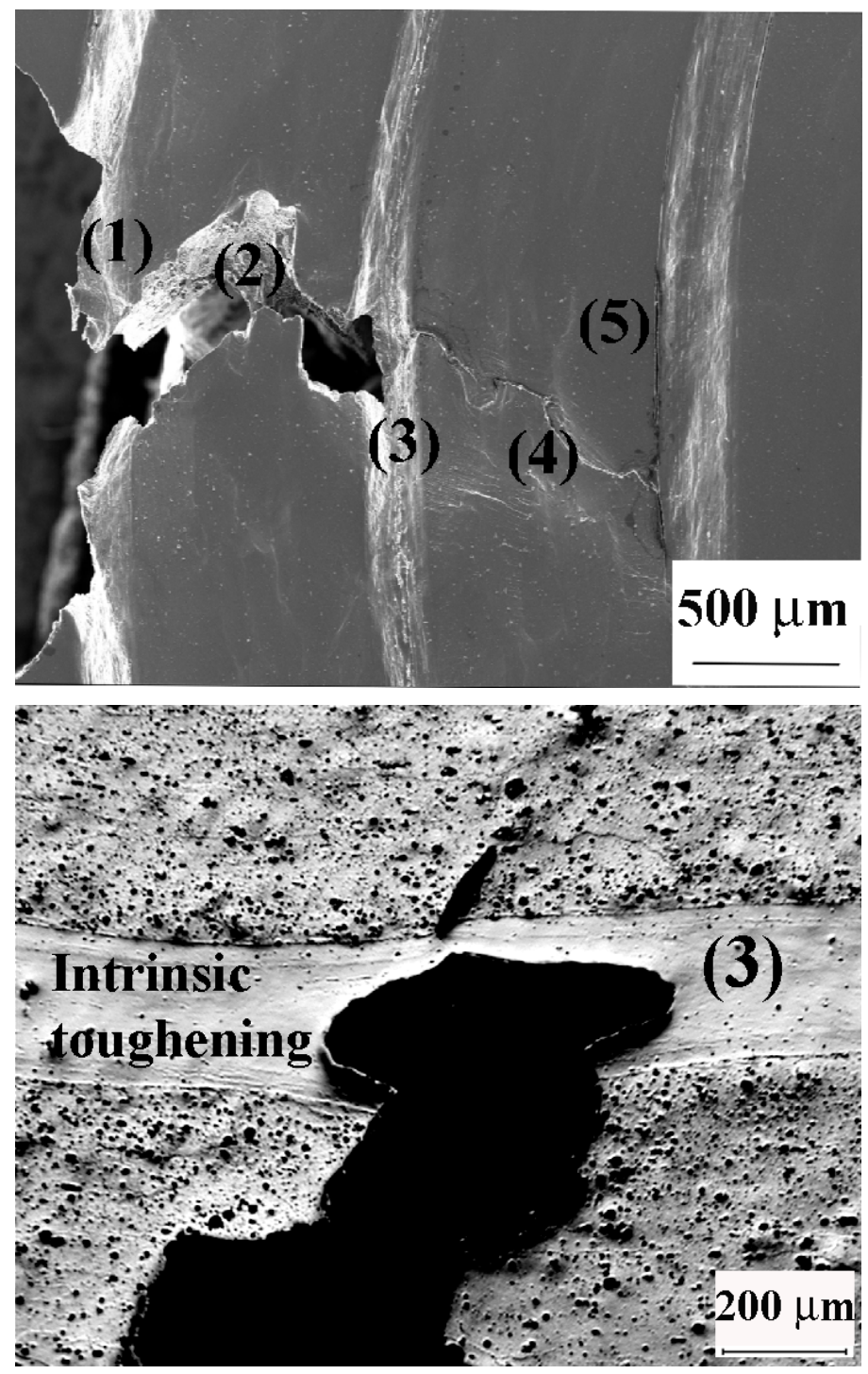

c)

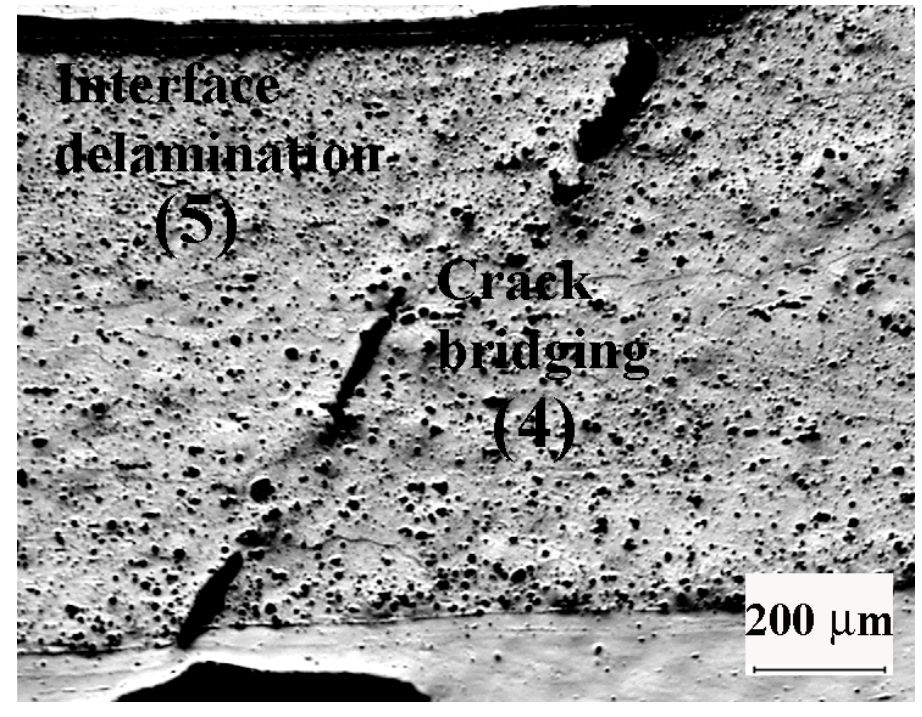

Figure 4 


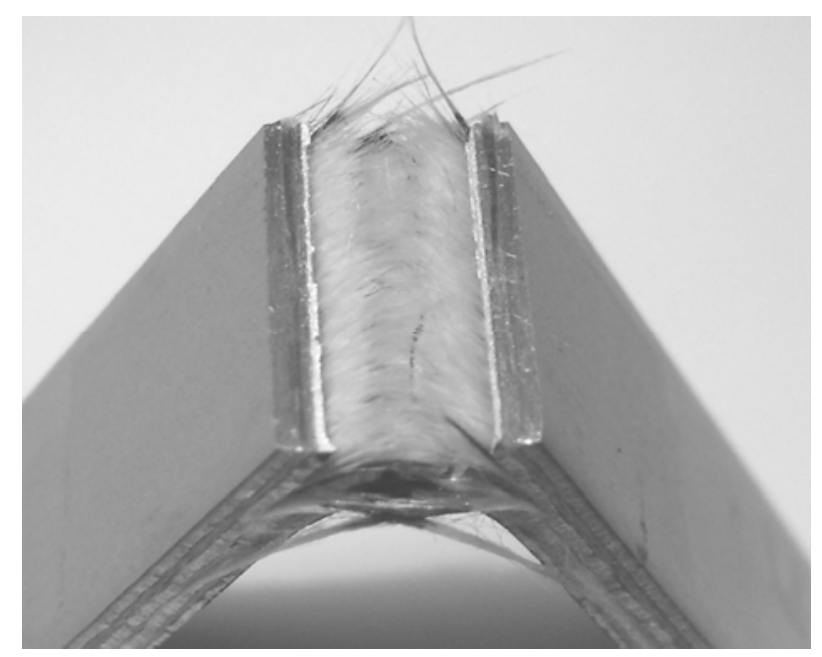

Figure 5

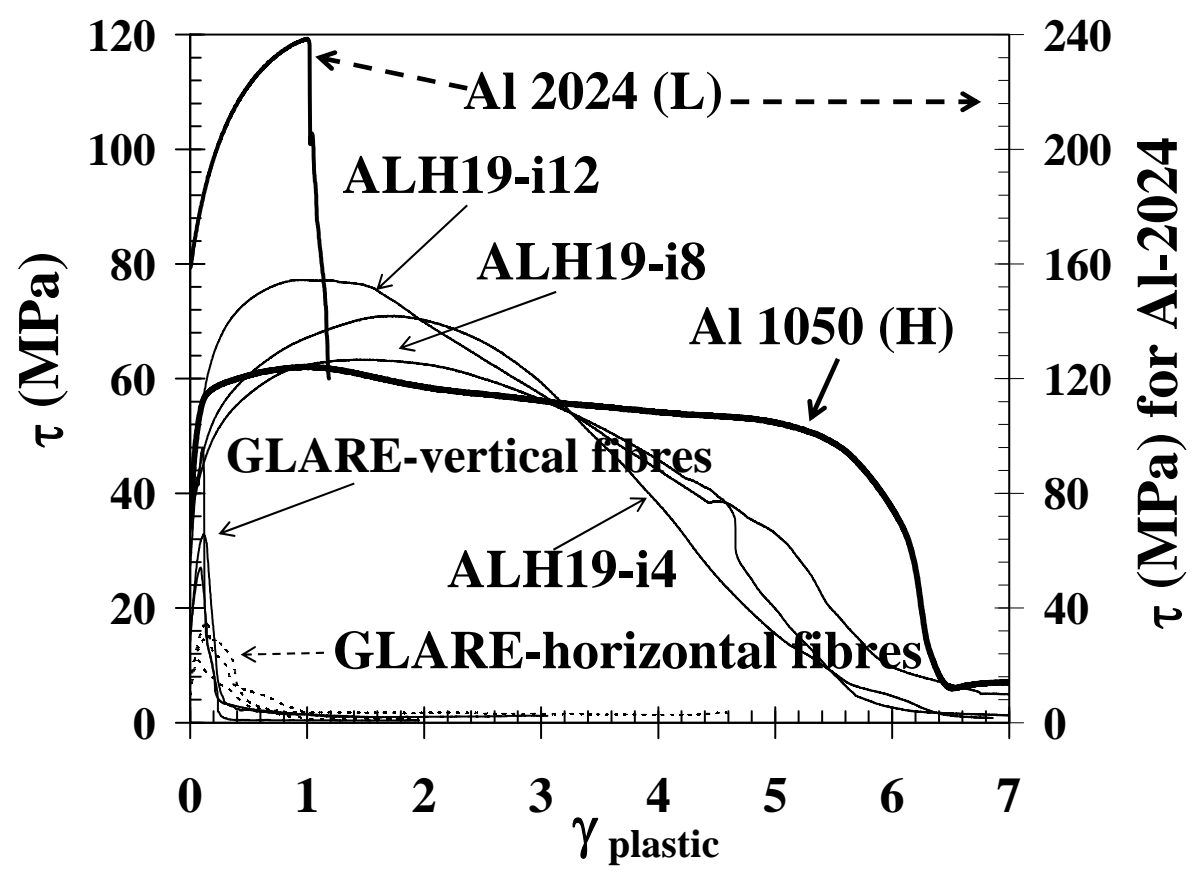

Figure 6 


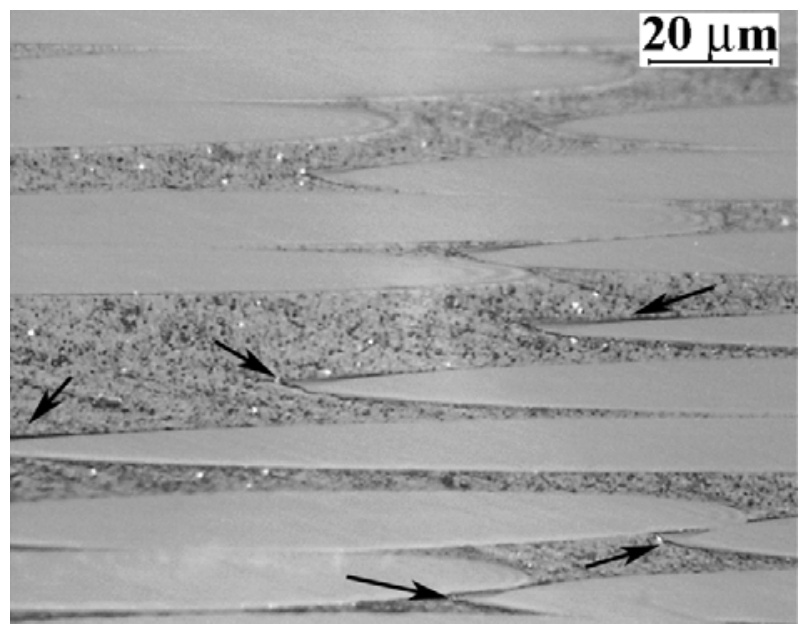

Figure 7 